\title{
Flexible hybrid circuit fully inkjet-printed: Surface mount devices assembled by silver nanoparticles-based inkjet ink
}

\author{
J. Arrese, G. Vescio, E. Xuriguera, B. Medina-Rodriguez, A. Cornet, and A. Cirera
}

Citation: Journal of Applied Physics 121, 104904 (2017); doi: 10.1063/1.4977961

View online: https://doi.org/10.1063/1.4977961

View Table of Contents: http://aip.scitation.org/toc/jap/121/10

Published by the American Institute of Physics

\section{Articles you may be interested in}

Wealth inequality: The physics basis

Journal of Applied Physics 121, 124903 (2017); 10.1063/1.4977962

Universal rules for visible-light absorption in hybrid perovskite materials

Journal of Applied Physics 121, 115501 (2017); 10.1063/1.4978071

Fully inkjet printed flexible resistive memory

Applied Physics Letters 110, 143503 (2017); 10.1063/1.4978664

Conversion of $p$ to $n$-type reduced graphene oxide by laser annealing at room temperature and pressure Journal of Applied Physics 121, 125303 (2017); 10.1063/1.4979211

Metal oxide semiconductor thin-film transistors for flexible electronics Applied Physics Reviews 3, 021303 (2016); 10.1063/1.4953034

Ultrathin lightweight plate-type acoustic metamaterials with positive lumped coupling resonant Journal of Applied Physics 121, 015102 (2017); 10.1063/1.4972839

\section{Scilight}

Sharp, quick summaries illuminating the latest physics research

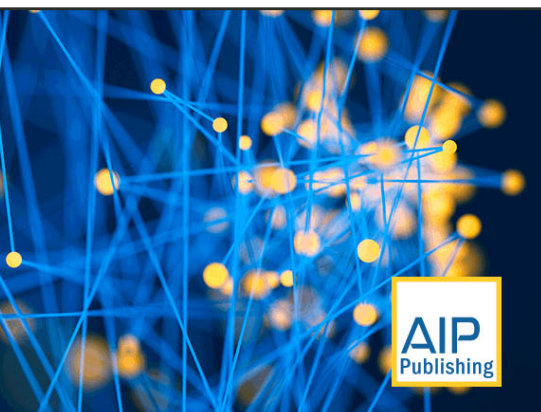




\title{
Flexible hybrid circuit fully inkjet-printed: Surface mount devices assembled by silver nanoparticles-based inkjet ink
}

\author{
J. Arrese,$^{\text {a) }}$ G. Vescio, E. Xuriguera, B. Medina-Rodriguez, A. Cornet, and A. Cirera \\ MIND-IN2UB, Department of Engineering: Electronics, Universitat de Barcelona, Martí i Franquès 1, \\ E-08028 Barcelona, Spain
}

(Received 30 November 2016; accepted 21 February 2017; published online 14 March 2017)

\begin{abstract}
Nowadays, inkjet-printed devices such as transistors are still unstable in air and have poor performances. Moreover, the present electronics applications require a high degree of reliability and quality of their properties. In order to accomplish these application requirements, hybrid electronics is fulfilled by combining the advantages of the printing technologies with the surface-mount technology. In this work, silver nanoparticle-based inkjet ink (AgNP ink) is used as a novel approach to connect surface-mount devices (SMDs) onto inkjet-printed pads, conducted by inkjet printing technology. Excellent quality AgNP ink-junctions are ensured with high resolution picoliter drop jetting at low temperature $\left(\sim 150^{\circ} \mathrm{C}\right)$. Electrical, mechanical, and morphological characterizations are carried out to assess the performance of the AgNP ink junction. Moreover, AgNP ink is compared with common benchmark materials (i.e., silver epoxy and solder). Electrical contact resistance characterization shows a similar performance between the AgNP ink and the usual ones. Mechanical characterization shows comparable shear strength for AgNP ink and silver epoxy, and both present higher adhesion than solder. Morphological inspections by field-emission scanning electron microscopy confirm a high quality interface of the silver nanoparticle interconnection. Finally, a flexible hybrid circuit on paper controlled by an Arduino board is manufactured, demonstrating the viability and scalability of the AgNP ink assembling technique. Published by AIP Publishing.
\end{abstract}

[http://dx.doi.org/10.1063/1.4977961]

\section{INTRODUCTION}

Printed electronics ${ }^{1}$ is a rapidly expanding research area, enabling low-cost, large-area, light-weight, and flexible electronics for bendable integrated circuits. ${ }^{2}$ Concerning this, several printing technologies have been developed to accomplish these electronics requirements. Gravure printing, ${ }^{3-5}$ screen printing, ${ }^{4,6,7}$ flexographic printing, ${ }^{3}$ laserinduced forward transfer printing, ${ }^{8}$ and inkjet printing ${ }^{9-14}$ find extensive applications in stretchable electronics. ${ }^{15,16}$

Among these techniques, drop-on-demand inkjet printing is a very promising printing technique since it guarantees high resolution that allows selective deposition, in a non-contact process, of a few picoliters amount of ink. ${ }^{17,18}$ Avoiding masks and vacuum systems, inkjet printing permits to attain fast prototyping of circuits, thus becoming a cost-efficient technology. Furthermore, inkjet printing can achieve, in particular, conditions, nanometric resolution by means of submicron droplet ejectors or using self-alignment methods. ${ }^{19,20}$

Despite the huge efforts made for formulating new functional inks, ${ }^{18,19,21,22}$ the main drawback in the inkjet printing technique is the lack of semiconductor and insulating inks. ${ }^{14,23,24}$ In fact, there are recent exciting advances in multi-layered electronic components, such as transistors, ${ }^{25-30}$ metal-insulator-metal (MIM) devices, ${ }^{31,32}$ organic light-emitting diodes (OLEDs), ${ }^{33}$ and diodes, ${ }^{4}$ towards fully inkjet-printed electronic circuits. ${ }^{34,35}$

\footnotetext{
${ }^{\text {a) }}$ Author to whom correspondence should be addressed. Electronic mail: xarrese@el.ub.edu
}

Nowadays, high technical requirements in electronic modules are fulfilled with hybrid techniques, combining the advantages of the printing technologies with the traditional components of surface-mount technology (SMT). ${ }^{36-40}$ The main issue related to this procedure is the surface-mount device (SMD) attachment onto inkjet patterned substrates. An usual material employed for SMT is reflow paste, ${ }^{41}$ a sticky mixture of flux and solder particles, but it shows incompatibility with inkjet-printed pads. Concerning this, solder particles on the reflow process were found to provoke a leaching effect by removing and damaging printed pads and generating undesired functional errors. ${ }^{38}$ Recently, Niittynen et al. implemented SMDs on inkjet-printed substrates by isotropically conductive adhesive (ICA) screen printing. ${ }^{38}$ Moreover, Andersson et al. assembled SMDs onto ink-jet printed paper with silver epoxy, solder, and conductive adhesive tapes. ${ }^{36,37}$

In this work, the recently patented use of silver nanoparticle-based inkjet ink (AgNP ink) as a new approach for assembling SMDs by means of high-resolution inkjet printing technology is presented. ${ }^{42}$ Taking advantage of surface energies existing at the nanoscale, AgNP ink ensures high electrical conductivity after the thermal process at very low temperatures, and thus a high electrical conductive interconnection, practically of $98 \%$ silver, is achieved. ${ }^{43-47}$ The new proposed method is compared with usual commercial benchmark materials employed for standard assembling. Therefore, AgNP ink, silver epoxy, and solder are tested on an inkjet-printed flexible and rigid substrate. Assembling methods' performance and their reliability were evaluated by means of electrical contact resistance and shear strength 
TABLE I. Electrical resistivity of the assembling materials used.

\begin{tabular}{lcc}
\hline \hline Manufacturer & Assembling material & Resistivity $(\mu \Omega \cdot \mathrm{cm})$ \\
\hline ANP, Silverjet DGP & AgNP ink & $\approx 16$ \\
Chemtronics, W2400 & Conductive silver epoxy Glue & $>10^{3}$ \\
Qualitek Sn97/Cu3 & Solder alloy Sn97/Cu3 & $>11,8$ \\
\hline \hline
\end{tabular}

of the SMDs onto the inkjet-printed pads. Finally, a fully inkjet-printed hybrid electronic circuit has been successfully manufactured onto paper substrate in order to show the feasibility of the new proposed method.

\section{EXPERIMENTAL DETAILS}

\section{A. Materials}

All the experimental tests were carried out by means of a printer machine Dimatix 2831 model series (Fujifilm USA). A cartridge with an ink droplet volume fixed at $10 \mathrm{pl}$ was used. For the printed pads and wires, Silverjet DGP HR (ANP, South Korea) with $40 \%$ of silver weight concentration with a viscosity around $\sim 16 \mathrm{cP}$ was used. The experimental set-up during printing processes was maintained stable at room temperature $\left(22^{\circ} \mathrm{C}\right)$, and meantime, nozzle firing drops and the inkjet platen substrate were fixed at $40^{\circ} \mathrm{C}$. Nozzleplaten with equal temperature was chosen to promote volatile solvent evaporation that ensures the best drop size on the surface after impacting the substrate.

Paper substrate Powercoat 230 (Arjowiggins, USA) with a thickness of $222 \mu \mathrm{m}$ and single faced adhesive plastic polyimide Kapton $^{\circledR}$ (ISOAD TAPE 7004, DuPont, USA) with a thickness of $25 \mu \mathrm{m}$ were used as flexible substrates. The paper substrate presents an organic coating around $\sim 15 \mu \mathrm{m}$ that prevents the paper in terms of ink penetration. A microscopy slide glass was employed as a rigid substrate.

Three materials were tested to assemble the SMDs onto the inkjet-printed pads: Silverjet ink compound, the same used for the inkjet-printed pattern; silver epoxy (CircuitWorks Conductive Epoxy CW2400, Chemtronix); and the solder (Qualitek, Sn 97\% Cu 3\%) after a previous flux (Omnifix) application on printed pads. The resistivity values are summarized in Table I. The resistivity values of selected assembling materials are specified by the manufacturers.

SMD resistors of $0 \Omega$ and model size 1206 (3.2 mm $\times 1.6 \mathrm{~mm}$ ) were selected for assembling characterization.

Concerning a fully printed hybrid electronic circuit on paper, carbon nanofibers (dispersed on isopropanol 70\% w/w) were deposited by drop coating onto inter-digit printed electrodes (supplementary material, S1) as an active layer for the humidity gas sensor, taking advantage of previous works of our group. ${ }^{48-50}$ A SMD NTC thermistor, case size $0402(1 \mathrm{~mm} \times 0.5 \mathrm{~mm})$, was used as a temperature sensor. SMD resistors, case sizes $0603(1.55 \mathrm{~mm} \times 0.85 \mathrm{~mm})$ and 0402, of different resistance values, properly estimated for the circuit requirements, were selected. Finally, SMD LED (LW P473 from OSRAM) was employed to obtain lightresponse information from the sensors. The fully inkjetprinted hybrid electronics circuit was controlled by an Arduino One board.

\section{B. Procedure}

Prior to the printing process, standard cleaning of the surface substrates was carried out (supplementary material, S2). A pattern of AgNP ink was printed and thermally cured in a convection oven at $150{ }^{\circ} \mathrm{C}$ for $30 \mathrm{~min}$, in order to evaporate the organic ink solvents and to sinter the silver nanoparticles to achieve a resistivity around $16 \mu \Omega \cdot \mathrm{cm}$, which is among the best values found in the literature. ${ }^{45,47,51}$ As a result, a pattern based on tracks and pads with an average thickness of $\sim 250 \mathrm{~nm}$ was deposited.

Inkjet-printed pads of two stripes $7 \mathrm{~mm} \times 1.6 \mathrm{~mm}$ with $1 \mathrm{~mm}$ pitch were printed as a fixed pattern set-up to carry out the electrical contact resistance study for each assembling test. Similarly, a fixed pattern consisting of two $5 \mathrm{~mm} \times$ $3 \mathrm{~mm}$ stripes with $1 \mathrm{~mm}$ pitch was printed to estimate the strength stress tests. In both cases, the study was realized with 30 samples for each assembling method.

In order to join the SMD metallic pads with the printed pads, by means of the AgNP ink, the SMDs were manually located onto the printed pads, and a well-adapted pattern was printed afterwards with the high resolution drop jetting printer (Fig. 1).

In the case of silver epoxy and solder, the processing steps were manually operated. Before soldering, adopting the iron at $200^{\circ} \mathrm{C}$, a proper plating of component pads was applied. Afterwards, SMDs were soldered onto AgNP inkprinted pads. The three different mounting techniques under test onto the three chosen substrates are shown in Fig. 2.

The hybrid circuit tracks and pads were also previously printed on a paper substrate and heat treated as can be observed in Figure 3.

\section{Characterization}

Resistance measurements were performed by means of a Keithley 2400 source meter with the 4-probe method. In order to obtain an accurate value of the contact resistance, SMD resistors of nominally $0 \Omega$ were measured to subtract (a)

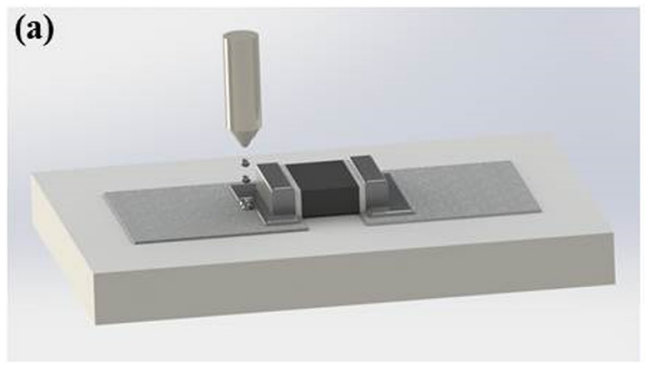

FIG. 1. (a) Illustration of the SMD AgNP ink assembling method. (b) SMD 0402 package of $0 \Omega \mathrm{AgNP}$ ink assembled. 
AgNP ink

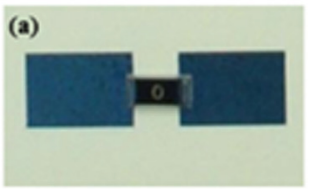

Paper
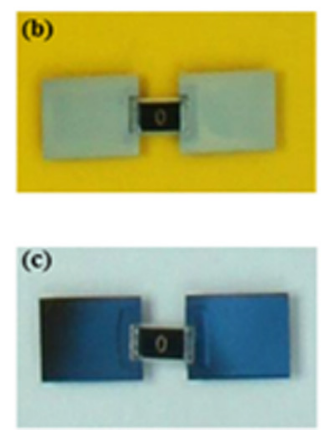

Silver epoxy
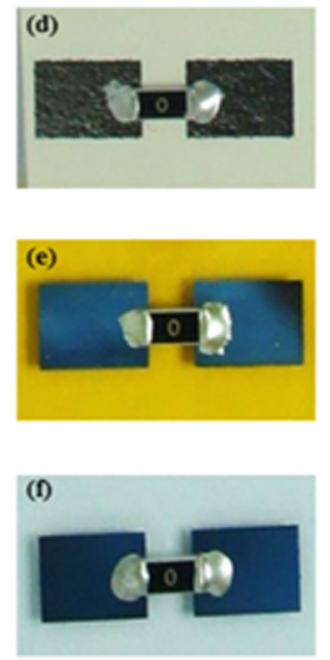

Solder
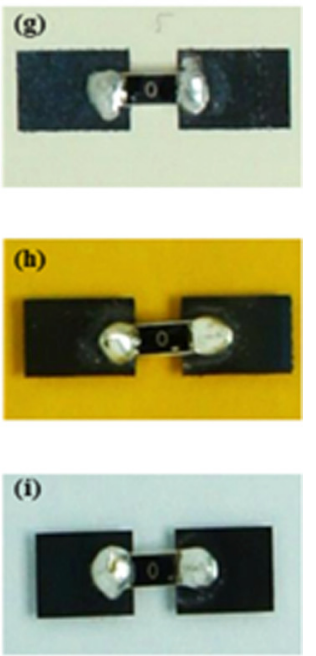

FIG. 2. Assembling SMDs on several substrates. (a)-(c) AgNP ink assembling method. (d)-(f) Silver epoxy assembling method. (g)-(i) Solder assembling method. The size of SMD devices is $3.2 \mathrm{~mm} \times 1.6 \mathrm{~mm}$. their background contribution from the contact-SMD system. Each value was divided by the two contact junctions. For each assembling method and substrate used, an average contact resistance was determined.

The shear strength analysis was conducted by means of a Zwich/Roell ZMART.PRO with a load cell with a nominal force of $200 \mathrm{~N}$. The evaluation test was done following the Japanese industrial standard for the mechanical tensile test called "Methods for shear strength of solder joints on chip components" (JIS Z 3198-7). The values of strength resistance, in $\mathrm{MPa}$, were obtained from the breaking force and the joined surfaces in parallel to the applied force direction.

The morphology of different junctions related to each assembling technique was inspected by using a Field Emission-Scanning Electron Microscope (FEI Nova 200). In order to observe the interface of junctions, samples were embedded in resin and subsequently polished.

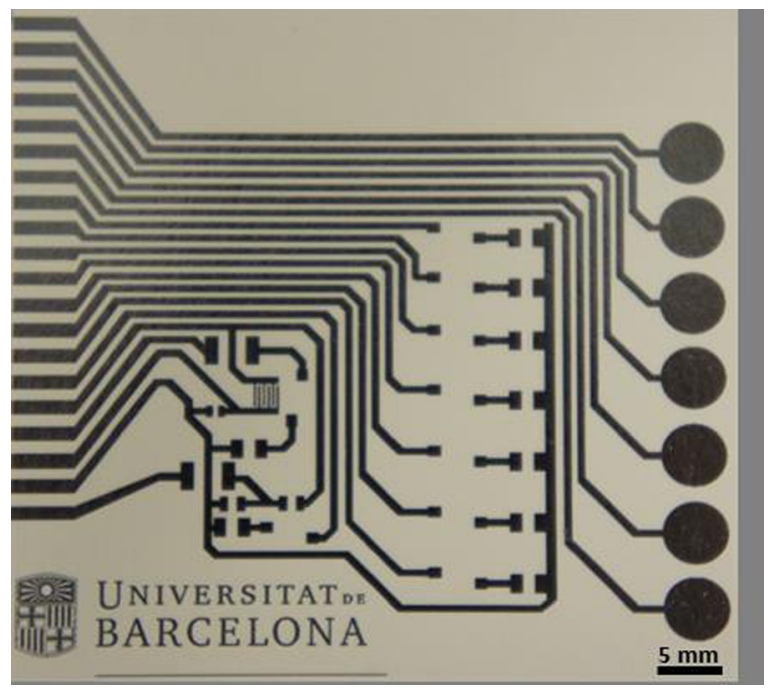

FIG. 3. Circuit pattern printed with AgNP ink on a paper substrate.

\section{RESULTS AND DISCUSSION}

The assembling performances were compared in terms of electrical, mechanical, and morphological properties in order to evaluate the reliability and feasibility of different techniques by an in-depth junction characterization.

Electrical contact resistance measurements were performed with the aim to demonstrate that a similar performance to benchmark materials can be achieved by the novel proposed assembling technique. The results are presented in Table II and Figure 4, taking into account the manufacturing failures. For each assembling method, all the badly attached components were considered as a failure and rejected. Then, considering the working devices (properly soldered), a contact resistance average value was estimated (a detailed example in the supplementary material, S3).

The roughness of the printed-paper surface plays an important role, impeding the interaction of the picoliter drop ink with the printed pad substrate and the SMD pad. The ink could not fill totally the interface between the inkjet-printed pad and the SMD pad, which would induce a weak junction. In order to solve this issue, the paper substrate that we selected is provided by a $\mathrm{CaCO}_{3}$ precoating. Ohlund et al. ${ }^{52,53}$ demonstrated that AgNP ink sintering could be impaired by the coating pore size but greatly enhanced by

TABLE II. Electrical contact resistance of assembled SMDs onto inkjetprinted pads depending on the attaching material and substrate.

\begin{tabular}{lccc}
\hline \hline Mounting method & Substrate & Contact resistance $(\Omega)$ & Failure (\%) \\
\hline AgNP ink & Paper $^{\mathrm{a}}$ & $0.27 \pm 0.09$ & 17 \\
& Kapton & $0.39 \pm 0.15$ & 17 \\
\multirow{3}{*}{ Silver Epoxy } & Glass & $0.37 \pm 0.10$ & 23 \\
& Paper & $0.56 \pm 0.07$ & 10 \\
\multirow{3}{*}{ Solder } & Kapton & $0.39 \pm 0.06$ & 13 \\
& Glass & $0.39 \pm 0.10$ & 10 \\
& Paper & $0.40 \pm 0.11$ & 3 \\
& Kapton & $0.12 \pm 0.05$ & 40 \\
\hline \hline
\end{tabular}

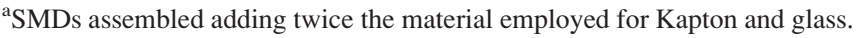




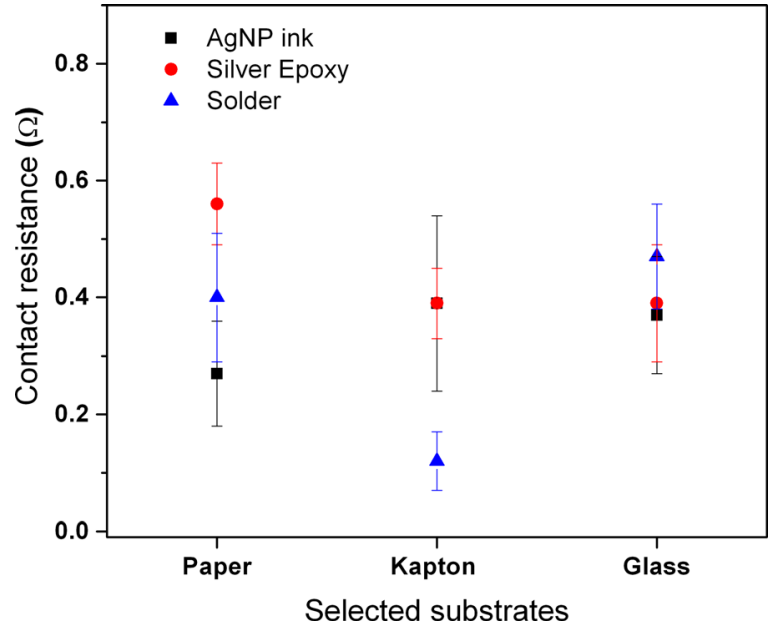

FIG. 4. Electrical contact resistance of assembled SMDs onto inkjet-printed pads depending on the attaching material and substrate.

using a porous $\mathrm{CaCO}_{3}$ precoating. They proved that small concentrations of $\mathrm{Cl}$ and $\mathrm{Ca}$ are present on the surface of the paper with $\mathrm{CaCO}_{3}$ precoating, and due to the presence of $\mathrm{Cl}$ in the AgNP ink, low temperature sintering with high conductivity values of printed pads can be facilitated by the presence of chloride. ${ }^{52,53}$

The precoating surface roughness and pore size, around 16-39 nm from the company datasheet, are small enough compared to the thickness of the printed layer $(\sim 1 \mu \mathrm{m})$. Therefore, in order to ensure the SMD assembling by AgNP ink, thick contacts were printed.

Regarding the smooth substrates glass and Kapton, high resolution drop size is ensured by a small value of contactangle (using flash volatile solvents that evaporate during drop in-flight), but consequently, the system droplet would be more inclined to generate coffee rings ${ }^{54}$ due to the non-uniform drying that leads to an excess of solute at the drop edges. The coffee ring effect was solved by the company, exploiting the Marangoni flow circulation in a drying drop, where, adding a proper co-solvent (triethylene glycol monoethyl ether) with a high boiling-point, a surface tension gradient is generated in order to reverse coffee-ring deposits. ${ }^{55,56}$

The best result for the electrical contact resistance was obtained on paper substrates with a value of $0.27 \pm 0.09 \Omega$. In the case of a glass substrate, the roughness of the SMD pad and glass surfaces contributes to promoting the capillarity effect and then increasing the connected surface area. The measured high conductive contacts between printed pads and AgNP solder during electrical tests could be due to a re-dispersion of the solvents from the printed top contact to the bottom pads, where silver nanoparticles can generate an interlayer with high conductive performance after a new sintering process without forming a percolation network. ${ }^{57}$ The other interlayer is promoted by the well-studied interaction between Ag nanoparticles and SMD Sn-plated. ${ }^{58}$

Similar electrical contact resistance values were obtained on a Kapton substrate, where the higher roughness of Kapton than that of glass seems to improve the junction reliability. In the case of a silver epoxy assembling material, the best results were achieved on Kapton and glass substrates. The electrical

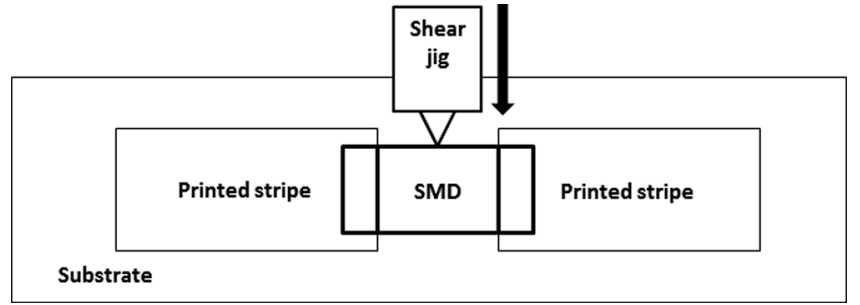

FIG. 5. Schematic of the tensile probe conducted according to the Japanese industrial standard JIS Z 3198-7.

contact resistance exhibited equivalent and comparable values to AgNP ink in spite of the utilization of a large amount of silver epoxy that implies both the material waste and a difficult high resolution assembling process.

Concerning the solder material, the best result was obtained on Kapton; however, the high number of failures showed lack of reliability. During the soldering process, degradation and displacement of the inkjet-printed pads due to the leaching effect were observed. ${ }^{38}$ Similar phenomena appeared slightly on glass and paper substrates. Solder achieved, on paper substrates, the best process reliability and a suitable value for electrical contact resistance.

In summary, all the three different tested assembling techniques showed an equivalent electrical resistance value, which allows stating the feasibility of the proposed AgNP ink as an alternative straight forward and cost-efficient interconnecting material.

Andersson et al. determined the lowest electrical contact resistance of $0.4 \pm 0.15 \Omega$ using a silver epoxy material to connect SMDs on inkjet-printed pads onto a paper substrate. ${ }^{37}$ This value is equivalent and comparable to the proposed AgNP ink on all different selected substrates. In addition, due to the high resolution drop jetting control, the proposed novel attaching technique is also cost-effective, avoiding the wasted material during the assembling process.

Shear strength measurements were performed with the aim to demonstrate that comparable performance to benchmark materials can be achieved by the proposed assembling technique. As previously mentioned, the methodology to perform the mechanical test under the Japanese standard is conducted as the following scheme (Fig. 5). The calculated shear strength values for the assembled SMD using AgNP ink, silver epoxy, and solder are shown in Table III and Figure 6, taking into account the manufacturing failures. The shear strength value for each mounting method was estimated by

TABLE III. Shear strength resistance of the SMD assembled onto inkjetprinted pads depending on the attaching material and substrate.

\begin{tabular}{lccc}
\hline \hline Mounting method & Substrate & Shear strength (MPa) & Failure (\%) \\
\hline \multirow{2}{*}{ AgNP ink } & Paper & $2.51 \pm 0.84$ & 7 \\
& Kapton & $2.16 \pm 0.79$ & 10 \\
\multirow{3}{*}{ Silver Epoxy } & Glass & $1.60 \pm 0.16$ & 13 \\
& Paper & $3.01 \pm 0.62$ & 3 \\
& Kapton & $1.87 \pm 0.37$ & 3 \\
Solder & Glass & $3.52 \pm 0.90$ & 3 \\
& Paper & $2.30 \pm 0.61$ & 3 \\
& Kapton & $1.03 \pm 0.50$ & 20 \\
& Glass & $0.55 \pm 0.44$ & 50 \\
\hline \hline
\end{tabular}




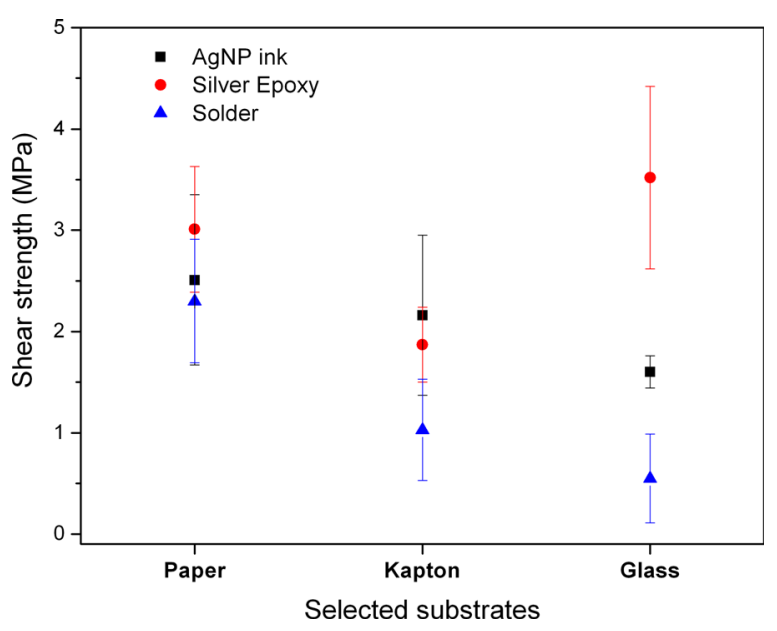

FIG. 6. Shear strength resistance of the SMD assembled onto inkjet-printed pads depending on the attaching material and substrate.

applying a similar modus operandi as done previously for the electrical measurements. Detailed information of characterization is presented in the supplementary material, S4.

With regard to the AgNP ink connecting material, the paper substrate showed the maximum shear strength value, followed by polyimide Kapton and glass substrates. Figure 7 presents evidence that the shear strength value is the result of two contributions: the interaction of the assembling material with printed pads and the adhesion strength of the printed pads onto the selected substrate. Indeed, the latter contribution is directly correlated with the roughness and porosity of the substrate.

With regard to the silver epoxy assembling material, the strongest adhesion was obtained on the glass substrate, and a comparable value was observed on the paper substrate.

The lowest shear strength, achieved with silver epoxy, was obtained with a Kapton substrate. The mechanical tests show greater epoxy remains on glass than on Kapton, demonstrating a better fixation between epoxy and printed pad on glass and justifying the higher shear strength reached (Figs. 8(b) and 8(d)). The adhesion results could be explained by different epoxy wettabilities onto each printed substrate. In the case of the solder connecting material, a general tendency to weaker shear strength than the previous assembling materials was observed in all the selected substrates. The strongest solder adhesion value was obtained on the paper substrate due to its considerable porosity and roughness that ensure a larger surface-area ratio than in the other substrates.

The mechanical test results confirmed that AgNP ink, exploiting the capillarity action in order to assemble the SMDs (Fig. 9(b)), performs as silver epoxy and is sturdier than solder. Fig. 9(b) shows how an isolated underlying contact point between the SMD pad and the inkjet-printed pad is produced by inkjet-printed AgNP ink. The electrical and mechanical study highlighted the AgNP ink as a promising alternative assembling material for SMDs.

To sum up, the proposed high resolution drop jetting technique sheds light on how, employing few picoliter drops, AgNP ink reveals comparable electrical and mechanical performances of benchmark assembling materials onto several inkjet-printed substrates.

Structural inspection of different junctions related to each assembling technique was performed to justify why the AgNP ink assembling technique exhibits competitive performances. Microscopic analyses of device cross-sections were performed by the FE-SEM technique, as shown in Fig. 10. The cross-sectional image of tin-plated SMD extremities displays the junction area between the surface device and inkjet-printed pad. Employing AgNP ink, the capillarity action moves the printed ink up to the underlying tin-plated SMD pads. Figures 10(b)-10(d) highlight the achieved
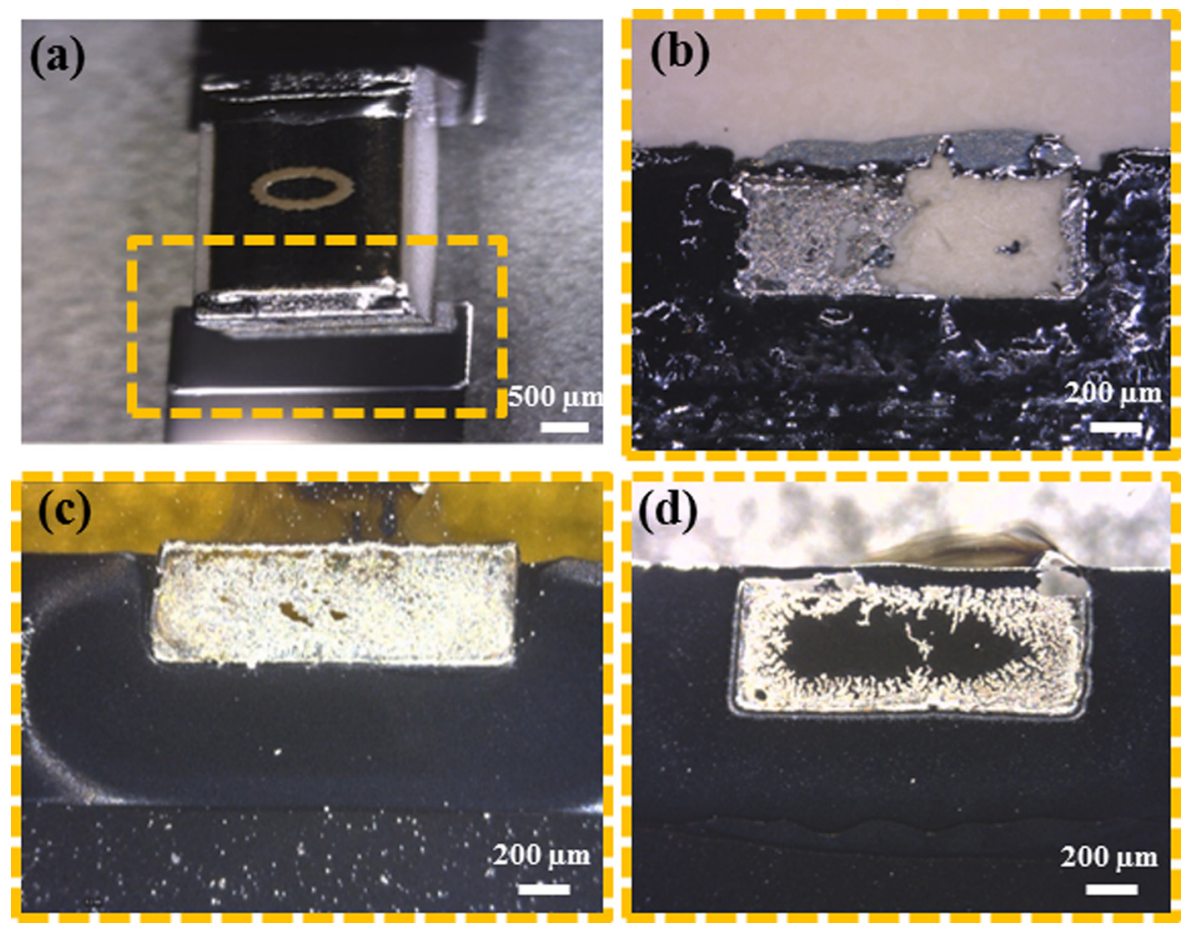

FIG. 7. (a) Image of SMD AgNP inkconnected on a glass substrate. (b)-(d) Pictures correspond to the substrate pad after removing SMD, AgNP inkattached, from paper, Kapton, and glass, respectively. All the cases show partially removed inkjet-printed pads. 

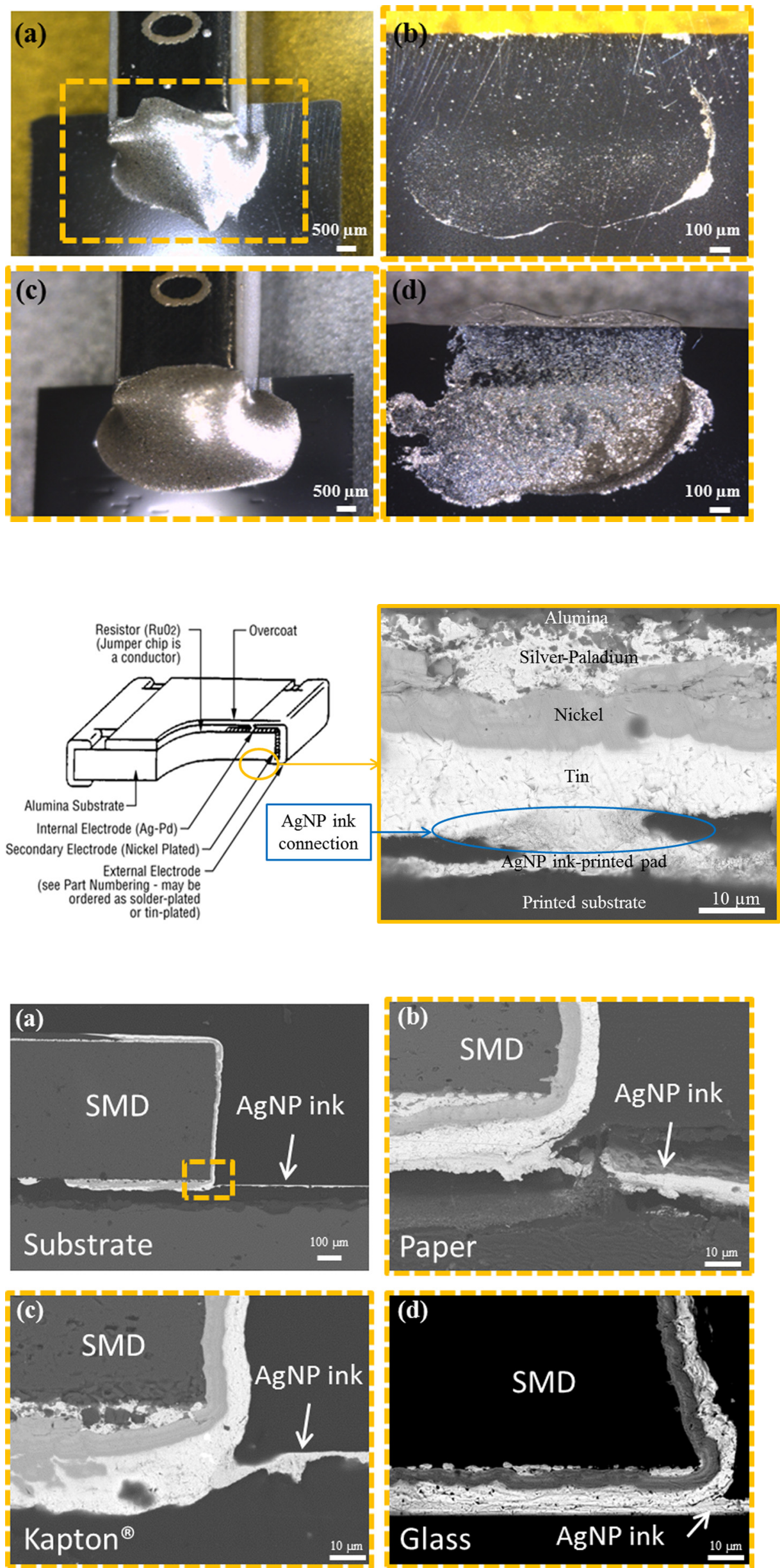

FIG. 8. (a) and (c) Optical images of the epoxy assembling before the shear strength test onto Kapton and glass, respectively. (b) and (d) Optical images of the epoxy assembling after the shear strength test onto Kapton and glass, respectively.
FIG. 9. (a) Schematic of the SMDs. (b) FE-SEM cross-sectional image of an isolated underlying contact area by AgNP ink between SMD tin-plated extremities and inkjet-printed solder pad. Furthermore, the description of the different layers is presented, proved by EDX analysis.
FIG. 10. (a) FESEM image of a crosssectional view of one SMD pad AgNP ink-assembled on a printed pad. (b)-(d) FE-SEM images correspond to the details of the junction zone of the SMD Sn-plated pad, AgNP ink connector inkjet-printed, and AgNP ink inkjetprinted pad on paper, Kapton, and glass substrates, respectively. 

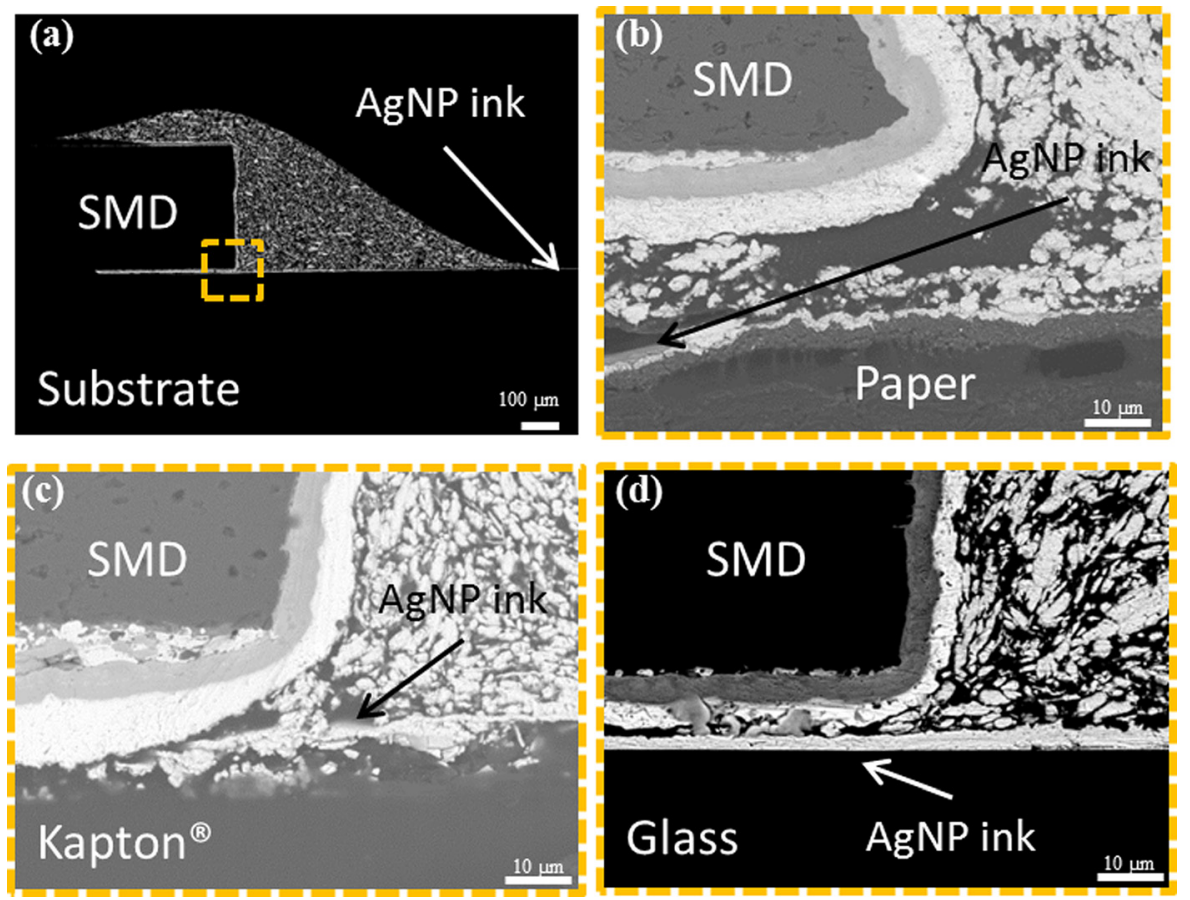

FIG. 11. (a) FE-SEM image of a crosssectional view of an SMD pad silver epoxy-assembled on an inkjet-printed pad. (b)-(d) FE-SEM images correspond to the details of the junction zone of the SMD Sn-plated pad, silver epoxy connector, and AgNP inkjet-printed pad on paper, Kapton, and glass substrates, respectively. excellent junction between printed connection and printed pad, which is proved by the indistinguishable bottom contact thickness contrast. The ink agglomerates almost uniformly down the edges of the SMD pads contributing to the high quality validated electrical contact and mechanical properties. In a different way than AgNP ink, devices connected by silver epoxy are not assisted by capillarity. Silver epoxy, manually applied, embeds the whole SMD pad area. However, the contact resistance measured is not better than with the AgNP ink assembling method. This is due to the existent adhesive filler mixed with the silver flakes in an approximately 50:50 ratio, as shown in Figs. 11(a)-11(d) by the dark zones between the bright silver particles. As previously reported about silver epoxy, in the same way, solder was manually deposited in order to assemble the SMD, as detailed in Fig. 12(a). Figs. 12(b)-12(d) point out a continuous junction interface between the soldering material and the inkjet-printed pad onto different selected substrates. As observed in the case of epoxy and due to lower conductivity than SNPI, an outwardly covered SMD pad does not ensure a better contact resistance.

Overall, FE-SEM images demonstrate that the assembling SMD technique by AgNP ink uniformly adapts and envelopes the Sn-plated SMD pads, without wasting unnecessary material
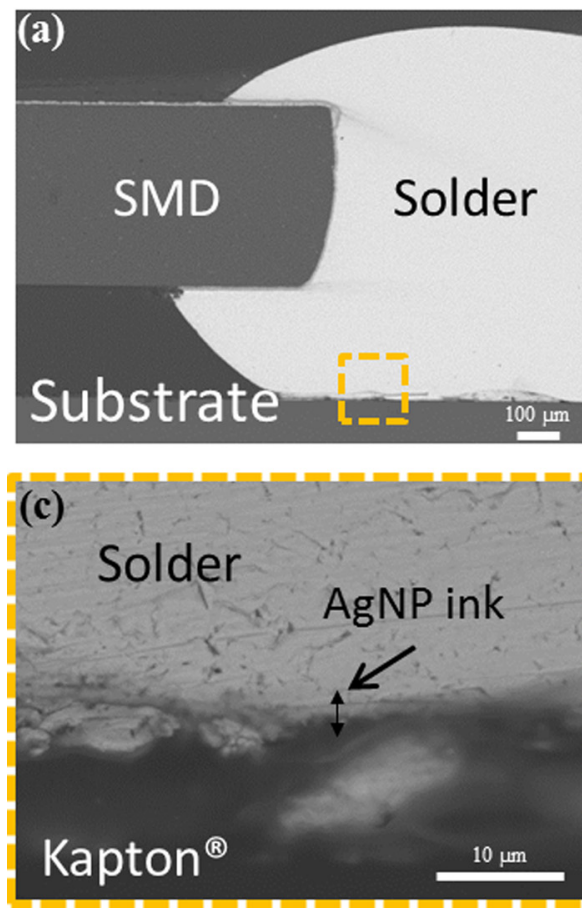

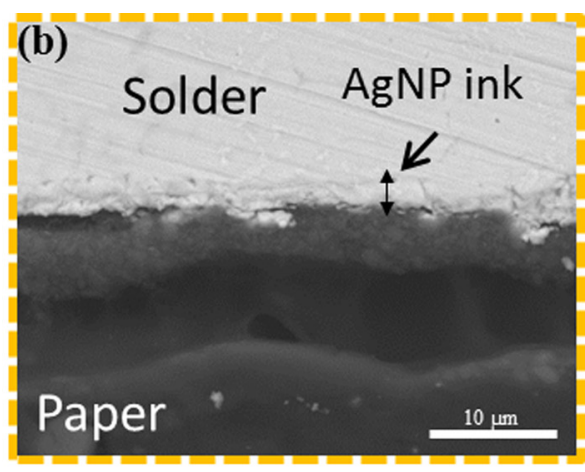

(d)

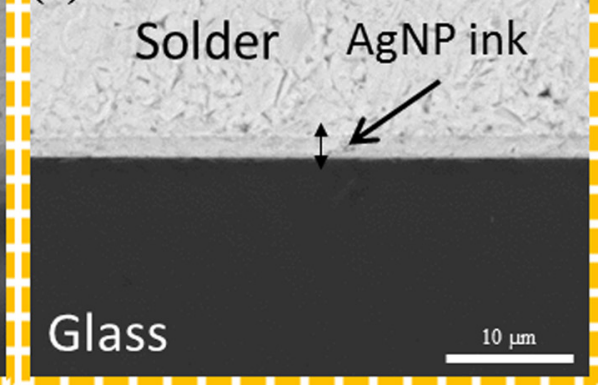

FIG. 12. (a) FESEM image of a crosssectional view of one SMD pad Sn assembled. (b)-(d) FE-SEM images correspond to the details of the junction zone of the solder connector and AgNP inkjet-printed pad on paper, Kapton, and glass substrates, respectively. 


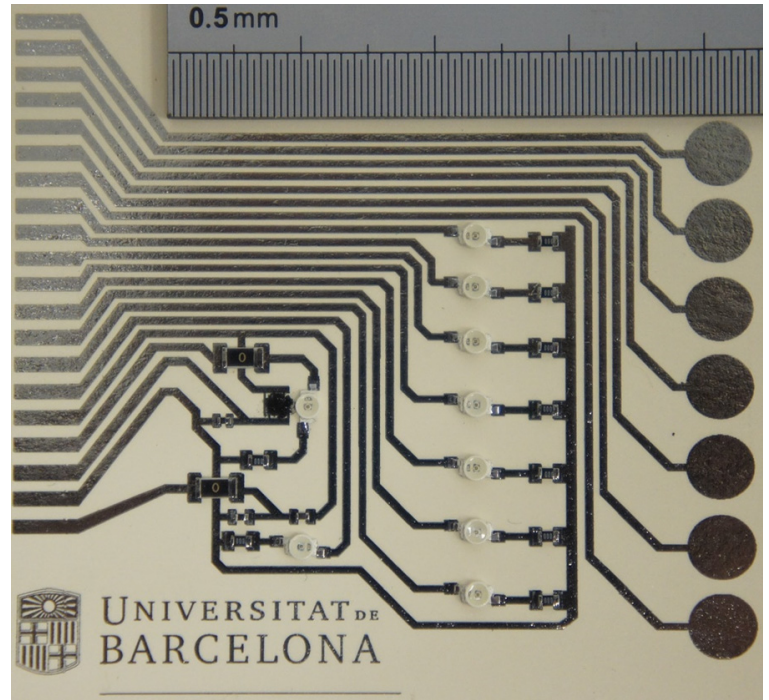

FIG. 13. Paper-based inkjet-printed electronic circuit with SMD AgNP inkconnected. (Multimedia view) [URL: http://dx.doi.org/10.1063/1.4977961.1]

surrounding the contact area as in the case of silver epoxy and solder methods. The structural characterization has shown that the morphology of the inkjet-printed silver connections evidences a solid and stable structure without detrimental fractures or pin-holes.

As practical demonstration of the proposed AgNP ink method, an inkjet-printed circuit with different families of assembled SMDs on paper is presented as shown in Fig. 13 and its associated video (Multimedia view).

The hybrid electronics circuit was controlled by Arduino One, which was programmed to monitor three different functional modes: capacitive touch control, temperature sensor, and humidity sensor. Each mode had a series of LEDs associated to easily visualize the information about the variation state. The supplementary material includes a demonstration video of the hybrid printed circuit and some complementary images (supplementary material, S5).

\section{CONCLUSIONS}

SMDs have been assembled successfully onto an inkjetprinted flexible and rigid substrate by AgNP ink using high resolution inkjet printing technology. AgNP ink was selectively printed in order to reach a homogeneous junction between SMD pads and printed stripes followed by a lowtemperature thermal treatment at $\sim 150^{\circ} \mathrm{C}$. Capillarity action of printed ink and coalescence sintering of silver nanoparticles ensures high quality soldering, promoted by $98 \%$ of interconnecting silver.

FE-SEM revealed the homogeneity and indiscernible contact between SMD and printed pads onto flexible substrates, paper, polyimide Kapton, and rigid glass substrate.

Electrical contact resistance and shear strength measurements proved drop-on-demand inkjet printing technology as a valid technique to incorporate on SMT, widening the applicability to stretchable and bendable substrates. In addition, high resolution and selective deposit of silver nanoparticles, exploiting the capillarity action, allows to avoid material waste (as in the case of silver epoxy and solder), thus maintaining high component density and fast assembling $(6 \mathrm{~m} / \mathrm{s})$.

Taking advantage of the proposed method, an intelligent flexible hybrid circuit was successfully achieved on paper, where SMDs of different sizes have been assembled by AgNP ink, demonstrating the reliability and feasibility of the proposed method to be implemented in a roll-to-roll manufacturing process.

In light of the all above-mentioned studies, an inkjet printing connecting technique is demonstrated as a promising method that allows selectively assembling integrated devices, in a non-contact process, onto inkjet-printed flexible and rigid substrates for upcoming hybrid electronics.

\section{SUPPLEMENTARY MATERIAL}

See supplementary material for more details about the cleaning procedure of used substrates. Moreover, an example of different test characterizations and fully printed hybrid circuit on a paper substrate is presented.

\section{ACKNOWLEDGMENTS}

The authors acknowledge Julio Rivera, Arturo Peitivi, and Sergio Llorente from BSH Electrodomésticos España, S.A. for their fruitful support and enlightening discussions. A. Cirera acknowledges 2015 edition of BBVA Foundation Grants for Researchers and Cultural Creators.

${ }^{1}$ M. Berggren, D. Nilsson, and N. D. Robinson, Nat. Mater. 6, 3 (2007).

${ }^{2}$ A. C. Siegel, S. T. Phillips, M. D. Dickey, N. Lu, Z. Suo, and G. M. Whitesides, Adv. Funct. Mater. 20, 28 (2010).

${ }^{3}$ H. Yan, Z. Chen, Y. Zheng, C. Newman, J. R. Quinn, F. Dötz, M. Kastler, and A. Facchetti, Nature 457, 679 (2009).

${ }^{4}$ F. C. Krebs, Sol. Energy Mater. Sol. Cells 93, 394 (2009).

${ }^{5}$ M. Pudas, N. Halonen, P. Granat, and J. Vähäkangas, Prog. Org. Coatings 54, 310 (2005).

${ }^{6}$ F. C. Krebs, M. Jørgensen, K. Norrman, O. Hagemann, J. Alstrup, T. D. Nielsen, J. Fyenbo, K. Larsen, and J. Kristensen, Sol. Energy Mater. Sol. Cells 93, 422 (2009).

${ }^{7}$ C. López-Gándara, J. M. Fernández-Sanjuán, F. M. Ramos, and A. Cirera, Solid State Ionics 184, 83 (2011).

${ }^{8}$ M. Colina, M. Duocastella, J. M. Fernández-Pradas, P. Serra, and J. L. Morenza, J. Appl. Phys. 99, 084909 (2006).

${ }^{9}$ I. Clancy, G. Amarandei, C. Nash, and B. A. Glowacki, J. Appl. Phys. 119, 054903 (2016).

${ }^{10}$ Y. Noda, H. Matsui, H. Minemawari, T. Yamada, and T. Hasegawa, J. Appl. Phys. 114, 044905 (2013)

${ }^{11}$ S. Claramunt, O. Monereo, M. Boix, R. Leghrib, J. D. Prades, A. Cornet, P. Merino, C. Merino, and A. Cirera, Sens. Actuators, B 187, 401 (2013).

${ }^{12}$ O. Monereo, S. Claramunt, M. M. De Marigorta, M. Boix, R. Leghrib, J. D. Prades, A. Cornet, P. Merino, C. Merino, and A. Cirera, Talanta 107, 239 (2013).

${ }^{13}$ H. Sirringhaus, T. Kawase, R. H. Friend, T. Shimoda, M. Inbasekaran, W. Wu, and E. P. Woo, Science 290, 2123 (2000).

${ }^{14}$ H. Minemawari, T. Yamada, H. Matsui, J. Tsutsumi, S. Haas, R. Chiba, R. Kumai, and T. Hasegawa, Nature 475, 364 (2011).

${ }^{15}$ S. H. Ko, J. Chung, H. Pan, C. P. Grigoropoulos, and D. Poulikakos, Sens. Actuators, A 134, 161 (2007).

${ }^{16}$ D. Tobjörk and R. Österbacka, Adv. Mater. 23, 1935 (2011).

${ }^{17}$ S. Magdassi and S. Magdassi, Pigm. Resin Technol. 16, 4 (1987), ISBN 9812818219.

${ }^{18}$ M. Singh, H. M. Haverinen, P. Dhagat, and G. E. Jabbour, Adv. Mater. 22, 673 (2010).

${ }^{19}$ T. Sekitani, Y. Noguchi, U. Zschieschang, H. Klauk, and T. Someya, Proc. Natl. Acad. Sci. U. S. A. 105, 4976 (2008).

${ }^{20}$ N. Zhao, M. Chiesa, H. Sirringhaus, Y. Li, Y. Wu, and B. Ong, J. Appl. Phys. 101, 064513 (2007). 
${ }^{21}$ H. Song, J. Spencer, A. Jander, J. Nielsen, J. Stasiak, V. Kasperchik, and P. Dhagat, J. Appl. Phys. 115, 17E308 (2014).

${ }^{22}$ S. Jeong, H. C. Song, W. W. Lee, Y. Choi, and B. H. Ryu, J. Appl. Phys. 108, 102805 (2010).

${ }^{23}$ A. Kamyshny and S. Magdassi, Small 10, 3515 (2014).

${ }^{24}$ H. W. Choi, T. Zhou, M. Singh, and G. E. Jabbour, Nanoscale 7, 3338 (2015).

${ }^{25}$ E. M. C. Fortunato, P. M. C. Barquinha, A. C. M. B. G. Pimentel, A. M. F. Gonçalves, A. J. S. Marques, L. M. N. Pereira, and R. F. P. Martins, Adv. Mater. 17, 590 (2005).

${ }^{26}$ N. Stutzmann, R. H. Friend, and H. Sirringhaus, Science 299, 1881 (2003).

${ }^{27}$ T. Y. Kim, M. Amani, G. H. Ahn, Y. Song, A. Javey, S. Chung, and T. Lee, ACS Nano 10, 2819 (2016).

${ }^{28}$ F. Torrisi, T. Hasan, W. Wu, Z. Sun, A. Lombardo, T. S. Kulmala, G.-W. Hsieh, S. Jung, F. Bonaccorso, P. J. Paul, D. Chu, and A. C. Ferrari, ACS Nano 6, 2992 (2012).

${ }^{29}$ C. Wang, J.-C. Chien, H. Fang, K. Takei, J. Nah, E. Plis, S. Krishna, A. M. Niknejad, and A. Javey, Nano Lett. 12, 4140 (2012).

${ }^{30}$ L. Huang, Y. Huang, J. Liang, X. Wan, and Y. Chen, Nano Res. 4, 675 (2011).

${ }^{31}$ G. Vescio, J. López-Vidrier, R. Leghrib, A. Cornet, and A. Cirera, J. Mater. Chem. C 4, 1804 (2016).

${ }^{32}$ Y. Liu, T. Cui, and K. Varahramyan, Solid. State. Electron. 47, 1543 (2003).

${ }^{33}$ S.-C. Chang, J. Liu, J. Bharathan, Y. Yang, J. Onohara, and J. Kido, Adv. Mater. 11, 734 (1999).

${ }^{34}$ J. Jiang, B. Bao, M. Li, J. Sun, C. Zhang, Y. Li, F. Li, X. Yao, and Y. Song, Adv. Mater. 28, 1420 (2016).

${ }^{35}$ S. E. Burns, P. Cain, J. Mills, J. Wang, and H. Sirringhaus, MRS Bull. 28, 829 (2003).

${ }^{36}$ H. Andersson, J. Sidén, V. Skerved, X. Li, and L. Gyllner, IEEE Trans. Compon. Packag. Technol. 6, 478 (2016).

${ }^{37}$ H. a Andersson, A. Manuilskiy, S. Haller, M. Hummelgård, J. Sidén, C. Hummelgård, H. Olin, and H.-E. Nilsson, Nanotechnology 25, 094002 (2014).

${ }^{38}$ J. Niittynen, J. Kiilunen, J. Putaala, V. Pekkanen, M. Mäntysalo, H. Jantunen, and D. Lupo, Microelectron. Reliab. 52, 2709 (2012).

${ }^{39}$ J. Putaala, J. Hannu, E. Kunnari, M. Mäntysalo, O. Nousiainen, and H. Jantunen, Microelectron. Reliab. 54, 272 (2014).
${ }^{40}$ V. Pekkanen, M. Mäntysalo, K. Kaija, P. Mansikkamäki, E. Kunnari, K. Laine, J. Niittynen, S. Koskinen, E. Halonen, and U. Caglar, Microelectron. Eng. 87, 2382 (2010).

${ }^{41}$ S. Xu, A. D. Pickel, A. Prasitthipayong, A. H. Habib, and M. E. McHenry, J. Appl. Phys. 113, 2011 (2013).

${ }^{42}$ J. Rivera, A. Peitivi, S. Llorente, X. Arrese, L. Servera, and A. Cirera, Spain patent ES 2564760 A1 (2014).

${ }^{43}$ K.-S. Moon, H. Dong, R. Maric, S. Pothukuchi, A. Hunt, Y. Li, and C. P. Wong, J. Electron. Mater. 34, 168 (2005).

${ }^{44}$ M. L. Allen, M. Aronniemi, T. Mattila, A. Alastalo, K. Ojanperä, M. Suhonen, and H. Seppä, Nanotechnology 19, 175201 (2008).

${ }^{45}$ H.-H. Lee, K.-S. Chou, and K.-C. Huang, Nanotechnology 16, 2436 (2005).

${ }^{46}$ S. Yan, D. Sun, Y. Gong, Y. Tan, X. Xing, G. Mo, Z. Chen, Q. Cai, Z. Li, H. Yu, and Z. Wu, J. Synchrotron Radiat. 23, 718 (2016).

${ }^{47}$ J. Perelaer, B. J. De Gans, and U. S. Schubert, Adv. Mater. 18, 2101 (2006).

${ }^{48}$ O. Monereo, S. Illera, A. Varea, M. Schmidt, T. Sauerwald, A. Schütze, A. Cirera, and J. D. Prades, Nanoscale 8, 5082 (2016).

${ }^{49}$ O. Monereo, J. D. Prades, and A. Cirera, Sens. Actuators, B 211, 489 (2015).

${ }^{50}$ O. Monereo, O. Casals, J. D. Prades, and A. Cirera, Sens. Actuators, B 226, 254 (2016)

${ }^{51}$ B. J. Perelaer, A. W. M. de Laat, C. E. Hendriks, and U. S. Schubert, J. Mater. Chem. 18, 3209 (2008).

${ }^{52}$ T. Öhlund, A. Schuppert, B. Andres, H. Andersson, S. Forsberg, W. Schmidt, H.-E. Nilsson, M. Andersson, R. Zhang, and H. Olin, RSC Adv. 5, $64841(2015)$.

${ }^{53}$ T. Öhlund, J. Örtegren, S. Forsberg, and H. E. Nilsson, Appl. Surf. Sci. 259, 731 (2012).

${ }^{54}$ R. D. Deegan, O. Bakajin, T. F. Dupont, G. Huber, S. R. Nagel, and T. A. Witten, Nature 389, 827 (1997).

${ }^{55} \mathrm{H}$. Hu and R. G. Larson, Langmuir 21, 3972 (2005).

${ }^{56}$ H. Hu and R. G. Larson, J. Phys. Chem. B 110, 7090 (2006).

${ }^{57}$ C. Nash, Y. Spiesschaert, G. Amarandei, Z. Stoeva, R. I. Tomov, and D. A. N. Tonchev, J. Electronic Mater. 44, 497 (2015).

${ }^{58}$ B. F. Dyson, J. Appl. Phys. 37, 2375 (1966). 